\title{
DETECCIÓN Y CONTROL DE DISCREPANCIAS FISCALES POR LA AUTORIDAD ADMINISTRATIVA
}

\author{
Detection and control of tax discrepancies by the administrative authority
}

\author{
María Angélica Nava Rodríguez
}

\begin{abstract}
Sumario:
I. Introducción. II. La discrepancia fiscal: concepto. III. Procedimiento de comprobación. IV. Definición de erogaciones. V. Antecedentes (adiciones y reformas) en 1981 y derogación en 1983. VI. Delito equiparable a defraudación fiscal a partir de 1992. VII. Adición en 2001 penúltimo párrafo y reforma del último párrafo del artículo 75 de la Ley del Impuesto sobre la Renta, de 2002 a la fecha adición y reforma a la Nueva Ley del Impuesto sobre la Renta, VIII. Conclusiones, IX. Bibliografía.
\end{abstract}

Resumen. La Discrepancia Fiscal se introdujo por primera vez en nuestro sistema jurídico cuando el país se encontraba comprometido con una deuda pública externa cuantiosa, seguramente en cumplimiento a "recomendaciones" de nuestros acreedores internacionales. La discrepancia fiscal es la diferencia que se origina cuando un contribuyente durante un año calendario realiza gastos e inversiones mayores comparadas con los ingresos declarados para efectos del pago de impuestos; constituye el eje principal por el cual las autoridades realizarán acciones de fiscalización a diversos sectores de contribuyentes y no contribuyentes, aplicando el procedimiento previsto en el artículo 107 de la Ley del Impuesto sobre la Renta.

Este precepto se ubica dentro del Título IV de las personas físicas en las "disposiciones generales", puesto que las personas morales nunca tendrán problemas de discrepancia fiscal ya que, los que gastan el dinero son los accionistas (personas físicas) de las sociedades, quienes incurren en discrepancia fiscal.

Palabras clave: discrepancia, defraudación, fiscalización

Abstract. The tax discrepancy was introduced for the first time in our legal system when the country was already committed to an external public debt substantial, probably in compliance to "recommendations" of our international creditors. The tax gap is the difference that originates when a taxpayer during a calendar year expenses $e$ investment higher compared with the income declared for the purposes of the payment of its taxes; it constitutes the main axis for which the authorities shall carry out inspection actions to various sectors of contributors and non-contributors, applying the procedure laid down in article 107 of the income tax act.

\footnotetext{
${ }^{1}$ Doctora en Derecho, con Maestrías en Derecho Fiscal, Administración Pública e Impartición de Justicia; por la UAT; con perfil PROMEP, labora en la UA de Derecho y CS de la Universidad Autónoma de Tamaulipas 
This precept is located within Title IV of physical persons in the "General provisions", since moral people will never have problems of fiscal discrepancy since those who spend the money are shareholders (physical persons) of the societies, who incur tax discrepancy.

Key words: discrepancy, fraud, drug control.

\section{INTRODUCCIÓN}

Los actos de fiscalización que realiza la autoridad administrativa a través de las visitas domiciliarias, se traducen en actos de molestia a los particulares, esta actividad fiscalizadora se puede realizar tanto en el domicilio de los contribuyentes como a través de revisiones de toda clase en los lugares de producción.; el procedimiento de fiscalización deberá estar debidamente fundado y motivado según lo ordenado por el art 16 constitucional.

Se debe tener presente que el artículo 16 de la Constitución Política de los Estados Unidos Mexicanos faculta a las autoridades administrativas a practicar visitas domiciliarias y exigir la exhibición de libros y papeles indispensables para comprobar que se han acatado las disposiciones fiscales, sujetándose en estos casos a las leyes respectivas y a las formalidades prescritas para los cateos.

Relacionando el artículo constitucional en comento con el artículo 42 del Código Fiscal de la Federación, se deduce la permisión a la autoridad fiscal para que realice diligencias tendientes a la revisión de la actividad del contribuyente, su contabilidad, bienes y mercancías.

Si de la revisión que la autoridad fiscal ejecuta llegara a detectar discrepancia entre los ingresos y las erogaciones, presumirá que hubo contribuciones omitidas; por tanto, el contribuyente para demostr2012 vigente.ar el origen de la discrepancia, quedará sujeto al procedimiento previsto por el artículo 107 de la Ley del impuesto sobre la renta (LISR) ${ }^{2}$, y de no probar documentalmente el origen de la discrepancia, la autoridad podrá determinar la existencia de ingreso gravable por el importe de esa discrepancia y fijar en su contra una liquidación.

Sánchez Miranda expresa en su obra Aplicación Práctica del Código Fiscal 2008, que éste es un ordenamiento jurídico rector de los procedimientos fiscales federales en el que se establecen los requisitos formales y de procedimiento que deben cumplirse en el desarrollo de una visita domiciliaria, los cuales tienen su fundamento en el artículo 16 Constitucional. 3.

\section{LA DISCREPANCIA FISCAL}

\section{CONCEPTO}

Según el diccionario de la Real Academia de la Lengua Española, la discrepancia es la diferencia o desigualdad que resulta de la comparación de las cosas entre sí. ${ }^{4}$

\footnotetext{
${ }_{2}$ Ley del Impuesto sobre la renta 2012

3 Sánchez, A .Aplicación práctica del Código Fiscal de la Federación, Revista PAF, edición 2008, México.

4 Diccionario Pequeño Larousse Ilustrado, (2012) editorial Artes gráficas, México. 
El Art. 107 de la LISR vigente por su parte señala que hay presunción de ingresos:

Cuando una persona física, aun cuando no esté inscrita en el Registro Federal de Contribuyentes, realice en un año de calendario erogaciones superiores a los ingresos que hubiere declarado en ese mismo año, se está ante la presencia de una discrepancia fiscal.

Lo anterior en principio permite presumir a las autoridades fiscales que la persona que se encuentre en este supuesto, obtuvo ingresos que no declaró y fueron utilizados para solventar sus erogaciones.

\section{PROCEDIMIENTO DE COMPROBACIÓN}

Las autoridades estarán obligadas a realizar el siguiente procedimiento con el fin de comprobar la discrepancia fiscal del contribuyente, por tanto:

I. Comprobarán el monto de las erogaciones y la discrepancia con los ingresos declarados por el contribuyente, debiendo dar a conocer a éste el resultado de dicha comprobación.

II. El contribuyente, en un plazo de quince días, informará por escrito a las autoridades fiscales las razones que tuviera para inconformarse o el origen que explique la discrepancia y ofrecerá las pruebas que estimare convenientes, las que acompañará a su escrito o rendirá a más tardar dentro de los veinte días siguientes. En ningún caso los plazos para presentar el escrito y las pruebas señaladas excederán, en su conjunto de treinta y cinco días.

III. Si no se formula inconformidad o no se prueba el origen de la discrepancia, ésta se estimará ingreso de los señalados en el Capítulo IX de este Título en el año de que se trate y se formulará la liquidación respectiva. ${ }^{5}$

Hasta aquí es claro que para que opere la discrepancia y se pueda activar un procedimiento a cargo de la persona física, se deben actualizar los siguientes supuestos:

1. Tener erogaciones en un año de calendario.

2. Que las erogaciones sean superiores a los ingresos declarados.

Para que quede perfectamente entendible cuándo se actualiza una discrepancia, es necesario determinar el alcance y el significado de los conceptos de erogaciones e ingresos declarados.

La Ley del Impuesto sobre la Renta considera como erogaciones a los gastos, las adquisiciones de bienes y los depósitos en cuentas bancarias o en inversiones financieras.

Como se puede observar para efectos de determinar la discrepancia fiscal de las personas físicas se incluye como erogaciones además de los gastos y la adquisición de bienes a los depósitos en cuentas bancarias o en inversiones financieras.

\footnotetext{
${ }^{5}$ Ley del ISR, Artículo 107, Fracciones I, II, III. Fisco agenda, 2011, Editorial ISEF, México.
} 
Para una mejor comprensión se definen cada uno de los conceptos considerados como erogaciones.

\section{DEFINICIÓN DE EROGACIONES}

Gastos. De acuerdo con el Diccionario de la Real Academia Española, gastar significa la acción de expender o emplear el dinero en una cosa o un servicio. ${ }^{6}$ En este caso el dinero sale del patrimonio del particular y como consecuencia de esta acción, se pierde el ámbito de su disponibilidad. Por ejemplo cuando contratamos un profesional, cuando arrendamos un bien, pagamos servicios públicos, etc.

Adquisición de bienes. En este sentido gastamos para adquirir bienes; sin embargo la diferencia entre este acto y el gasto genérico es que, en el primer caso la erogación del dinero se transforma en una bien ya sea mueble o inmueble generando con ello patrimonio, y en la acción de gastar, el patrimonio se pierde.

Depósitos en cuentas bancarias o inversiones financieras. En este caso no estamos ante un gasto o una adquisición de un bien, sino ante un acto jurídico o contrato de depósito regulado en la Ley General de Títulos y Operaciones de Crédito (LGTOC) ${ }^{7}$ y en las Leyes que regulan la operación del sistema financiero, tales como las instituciones de crédito. ${ }^{8}$

En el depósito de una suma determinada de dinero se procede a transferir la propiedad del dinero al depositario o deudor (La Institución Financiera), constituyéndose en este acto relación deudor/acreedor, como consecuencia el deudor se obliga a restituir la suma depositada con o sin interés.

Es necesario aclarar que las erogaciones para efectos de determinar la discrepancia fiscal, en una persona física, se considerarán aún cuando no cumplan con requisitos fiscales y estén o no declaradas. Otro punto trascendente es el hecho de que los depósitos en cuentas bancarias se asimilan a una erogación para estos propósitos.

Se debe considerar que si una persona obtiene un ingreso y lo deposita íntegramente, en principio debió declararlo aún y cuando esté exento, esto daría como resultado que para efectos de medir si esta persona está ante una discrepancia fiscal, que la autoridad comparará las erogaciones en este caso el monto del depósito contra el ingreso declarado que para este caso coincide con el monto de las erogaciones (depósitos), por lo que no resultaría discrepancia. ${ }^{9}$

Por el contrario, es decir, que si dichos Ingresos no hubieran sido declarados, lógicamente las erogaciones efectuadas serán superiores a los ingresos declarados, en este caso, la persona física de que se trate si presenta discrepancia fiscal.

Por lo anterior tanto los depósitos bancarios como las inversiones financieras forman parte de las erogaciones sujetas a discrepancia fiscal.

\footnotetext{
${ }^{6}$ Diccionario Pequeño Larousse de la Real Academia Española, p. 522

7 Ley General de Títulos y Operaciones de Crédito, el monto total de las erogaciones realizadas por una persona dentro de un ejercicio fiscal, es con el fin de conocer su capacidad Económica.

8 www.alvarezcarmona.com/boletines/PDF_topico/discrepancia.pdf

${ }^{9}$ www.alvarezcarmona.com/boletines/PDF_topico/discrepancia.pdf 


\section{ANTECEDENTES DE LA DISCREPANCIA FISCAL}

El $1^{\circ}$ de enero de 1980 entró en vigor el segundo párrafo del artículo 48 de la Ley del Impuesto sobre Renta del 30 la de diciembre de 1978, y por primera vez se detectó la Discrepancia Fiscal al establecerse lo siguiente: ${ }^{10}$

"Cuando una persona física realice en un año de calendario erogaciones superiores a los ingresos que hubiera declarado en ese mismo año, las autoridades fiscales procederán como sigue:

I.-Comprobarán el monto de las erogaciones y la discrepancia con la declaración del contribuyente y darán a conocer a éste el resultado de dicha comprobación.

II.-El contribuyente en un plazo de veinte días, informará por escrito a la autoridad fiscal las razones que tuviera para inconformarse o el origen que explique la discrepancia y ofrecerá pruebas que estimare convenientes, las que acompañará con su escrito o rendirá a más tardar dentro de los cuarenta y cinco días siguientes.

III.- Si no se formula inconformidad o no se prueba el origen de la discrepancia, ésta se estimará ingresos de los señalados en el Capítulo IX de este Título en el año de que se trate y se formulará la liquidación respectiva.

IV.-Las discrepancias que resulten de la aplicación de este precepto, no serán consideradas como constitutivas del delito de defraudación fiscal". ${ }^{11}$

\section{ADICIÓN A PARTIR DE 1981 Y DEROGACIÓN EN 1983}

$\mathrm{El} 1^{\circ}$. De enero de 1981 entró en vigor una nueva Ley del Impuesto sobre la Renta que abrogó a la anterior del 30 de diciembre de 1964.

La disposición contenida en el segundo párrafo del artículo 48 de la Ley del Impuesto sobre la Renta del 30 de diciembre de 1964, se incluyó en el artículo 75 de la nueva Ley del ISR, sustancialmente en los mismos términos, sólo adicionándosele un último párrafo que disponía que "Cuando el contribuyente no presente declaración anual estando obligado a ello, se aplicará este precepto como si lo hubiera presentado sin ingresos."

En 1983 se Derogó la Fracción IV del Artículo 75 de la Ley del Impuesto sobre la Renta, que disponía que "IV. Las discrepancias que resulten de la aplicación de este precepto, no serán consideradas como constitutivas del delito de defraudación fiscal”.

En diciembre de 1991 se simuló la farsa de que el texto definitivo la adición referida no lo determinó el Poder Ejecutivo o la Secretaría de Hacienda y Crédito Público, sino supuestamente la Comisión de Hacienda de la Cámara de Diputados, lo que es imposible que haya sucedido ya que los diputados carecen de tiempo, preparación y conocimientos en materia fiscal, por lo que no es creíble que ellos hayan sido los autores del texto en cuestión.

\footnotetext{
${ }^{10}$ LISR, México, diciembre de 1978.

${ }^{11}$ En la fracción IV del artículo 48 de la ley del ISR, establecía que las discrepancias fiscales no serían consideradas como constitutivas del delito de defraudación fiscal.
} 
En la iniciativa en mención, el Ejecutivo Federal Propuso esta adición a la fracción I del artículo 109 del Código Fiscal de la Federación, pero con el siguiente texto, intencionalmente defectuoso e impreciso:

"I. Consigne en las declaraciones que presente para efectos fiscales, deducciones falsas o ingresos menores a los realmente obtenidos y EN EL CASO DE ACTIVIDADES EMPRESARIALES, DIVIDENDOS HONORARIOS Y EN GENERAL POR LA PRESTACION DE UN SERVICIO PERSONAL INDEPENDIENTE, ESTOS INGRESOS SE HAYAN COMPROBADO DEBIDAMENTE”. (Art. 109 fracción I, LISR, 1991). ${ }^{12}$

La comisión de Hacienda de la Cámara de Diputados, "sabiamente" expresó en su Dictamen que "Por lo que se refiere a la propuesta de reformar la fracción I del artículo 109, para establecer un supuesto adicional de ilícito fiscal sancionable con las mismas penas del delito de defraudación fiscal, esta Comisión Legisladora considera que se deben precisar los plazos y procedimientos a los que deberán sujetarse los supuestos de dicho ilícito. El objetivo que percibe esta Comisión es el de otorgar una mayor seguridad jurídica al contribuyente, y que no sea una simple presunción de la autoridad la que lo lleve a ser sujeto de un proceso penal, sin que antes se le otorgue la posibilidad de demostrar y justificar en qué se fundan las erogaciones realizadas cuando éstas sean superiores a los ingresos declarados, ya que no necesariamente se debe considerar que el contribuyente está realizando una conducta delictiva en perjuicio del fisco federal, al realizar erogaciones superiores a sus ingresos.

Por tal motivo, esta Comisión considera conveniente establecer en la disposición que se comenta, que las discrepancias entre erogaciones e ingresos declarados, deben comprobarse ante la autoridad fiscal, recurriéndose para ello al procedimiento establecido en el artículo 75 de la Ley de Impuesto Sobre la Renta, otorgándose de esta forma una mayor seguridad jurídica al respetarse las garantías constitucionales del contribuyente, en virtud de que por un lado, la autoridad deberá cumplir las formalidades establecidas en dicho procedimiento, y por otro, el contribuyente tendrá posibilidad de desvirtuar lo afirmado por la autoridad.

En este contexto, se obliga a la autoridad a que, en caso de encontrar discrepancias entre los ingresos declarados y las erogaciones realizadas, deba comprobarlas y notificarle al contribuyente dicho resultado, para que éste a su vez, dentro del plazo de 20 días que establece el precepto referido pueda inconformarse o explicar el origen de tal discrepancia, ofreciendo las pruebas que estime convenientes, las cuales se podrán desahogar en un plazo de 45 días, para con ello poder desvirtuar los hechos imputados por la autoridad. Una vez que la autoridad fiscal cumpla con el procedimiento señalado, y si no se prueba el origen de la discrepancia, podrá entonces acudir a las autoridades competentes a querellarse por el hecho considerado como delictuoso, para que sea la autoridad judicial la que resuelva lo conducente...", supuestamente proponiendo a continuación el texto que finalmente fue aprobado en sus términos exactos, el cual ha quedado reproducido al inicio de este apartado. (Cámara de Diputados, 1991).

\section{DELITO EQUIPARABLE A DEFRAUDACIÓN FISCAL A PARTIR DE 1992}

Un aspecto de alta trascendencia es que no sólo el hecho de generar una discrepancia fiscal se provoca en el ejercicio en donde una persona física realiza erogaciones mayores a los

\footnotetext{
${ }^{12}$ Art. 109 fracción I, LISR, México 1991 
ingresos declarados, a partir del El 1 ${ }^{\circ}$. De enero de 1992 entró en vigor una adición a la fracción I del artículo 109 del Código Fiscal de la Federación, donde se previó que esta situación podría derivar en la configuración de un delito equiparable a la defraudación fiscal, en los términos del artículo 109 del CFF. Que textualmente reza:

Artículo 109 CFF. Será sancionado con las mismas penas del delito de defraudación fiscal, quien: I. Consigne en las declaraciones que presente para los efectos fiscales, deducciones falsas o ingresos acumulables menores a los realmente obtenidos o determinados conforme a las leyes. En la misma forma será sancionada aquella persona física que perciba dividendos, honorarios o en general preste un servicio personal independiente o esté dedicada a actividades empresariales, cuando realice en un ejercicio fiscal erogaciones superiores a los ingresos declarados en el propio ejercicio y no compruebe a la autoridad fiscal el origen de la discrepancia en los plazos y conforme al procedimiento establecido en el artículo 75 de la Ley del Impuesto sobre la Renta.

En este orden de ideas, Sergio Francisco de la Garza, al tratar el tema de los delitos fiscales señala que : "son aquéllos ilícitos o infracciones en sentido lato, que se distinguen de las contravenciones en virtud de que establecen penas que por su naturaleza puede imponer sólo la Autoridad Judicial, como son los que importan privación de la libertad". Mencionando entre otros La Defraudación Fiscal y los hechos asimilados a ésta, dentro de los cuales se ubicaría la Discrepancia Fiscal. ${ }^{13}$

Por su parte Doricela Mabarak, dice que el delito se configura cuando la conducta ilícita ofende al orden social en forma que requiere una pena más rigurosa que la propia sanción administrativa...y continúa afirmando que los delitos fiscales pertenecen al grupo de los delitos especiales, por tanto, su tipificación y tratamiento quedan fuera de la legislación penal común; por lo que la discrepancia al no estar tipificada en el código fiscal, requiere un trato especial, pues sería considerada una conducta asimilada a la defraudación, pero que no cuenta con todos los elementos de ésta. ${ }^{14}$

Afirma Gregorio Sánchez que los delitos innominados o equiparables a otros, deberán ser sancionados con las mismas penas que corresponden al delito al cual se asimilan, en consecuencia la discrepancia fiscal será sancionada con la penalidad de la defraudación fiscal.

El 1 ${ }^{\circ}$. De enero de 1997 se reformó la fracción II del artículo 75 de la Ley del Impuesto sobre la Renta, sólo para sustituir los plazos originales de 20 y 45 días respectivamente, por los de 15 y 20 días, adicionándole el señalamiento de que “... “...En ningún caso los plazos para presentar el escrito y las pruebas señaladas excederán en su conjunto de treinta y cinco días”.

Adición en 2001 penúltimo párrafo y reforma del último párrafo del Artículo 75 de la Ley del Impuesto sobre la Renta.

El $1^{\circ}$. De enero de 2001 se adicionó un penúltimo párrafo al artículo 75 de la Ley del Impuesto sobre la Renta que disponía que "Para los efectos de esté artículo se consideran erogaciones, los gastos, las adquisiciones de bienes y los depósitos en inversiones financieras. No se tomarán en consideración los depósitos que el contribuyente efectúe en cuentas que no sean propias, que califiquen como erogaciones en los términos de este artículo, cuando se demuestre que dicho depósito se hizo como pago de adquisiciones de bienes o servicios, o como contraprestación para el otorgamiento del uso o goce temporal de bienes o para realizar inversiones financieras, ni los traspasos entre cuentas del contribuyente, o a cuentas de su cónyuge, de sus ascendientes o descendientes en línea recta en primer grado”, reformándose

\footnotetext{
${ }^{13}$ Garza de la, S. (2005) “Derecho Financiero Mexicano”, 17. Edición, Editorial Porrúa, México.

${ }^{14}$ Mabarak, D. (200o), "Derecho Financiero Público”, 2a Edición, Editorial Mc GRAW-HILL, México.
} 
su último párrafo, que a partir de esa fecha dispuso que "Cuando el contribuyente OBTENGA INGRESOS DE LOS PREVISTOS EN ESTE TITULO y no presente declaración anual, se aplicará este precepto como si la hubiera presentado sin ingresos".(LISR, 2001,ART.75).

\section{ADICIÓN Y REFORMA EN LA NUEVA LEY DEL IMPUESTO SOBRE LA RENTA.}

El $1^{\circ}$. De enero de 2002 entró en vigor una nueva LISR, que abrogó a la anterior del 30 de diciembre de 1980 .

La disposición contenida en el artículo 75 de la Ley del Impuesto sobre la Renta del 30 de diciembre de 1980, se incluyó en el artículo 107 de la nueva Ley; sustancialmente en los mismos términos, sólo reformándose el anterior último párrafo del artículo 75 aludido, a partir de esa fecha penúltimo párrafo del artículo 107 de nueva Ley, que dispone que "Cuando el contribuyente obtenga ingresos de los previstos en este Título y no presente declaración anual estando obligado a ello, se aplicará este precepto como si la hubiera presentado sin ingresos.

Tratándose de contribuyentes que no estén obligados a presentar declaración del ejercicio, se consideran, para los efectos del presente artículo, los ingresos que los retenedores manifiesten haber pagado al contribuyente de que se trate", y adicionándosele un último párrafo al artículo 107 de la nueva LISR que dispone que "Se presume, salvo prueba en contrario, que los préstamos y los donativos, a que se refiere el segundo párrafo del artículo 106 de esta ley, que no sean declarados conforme a dicho precepto, son ingresos omitidos de la actividad preponderante del contribuyente o, en su caso, son otros ingresos en los términos del capitulo IX de este título, por los que no se pagó el impuesto correspondiente" (LISR 2002,Art.107).

El último párrafo del artículo 107 de la Ley del Impuesto sobre la Renta está relacionado con el segundo párrafo del artículo 106 de dicha Ley, que en 2002 disponía que "Las personas físicas residentes en México están Obligadas a informar, en la declaración del ejercicio, sobre los préstamos, los donativos y los premios obtenidos en el mismo, siempre que éstos, en lo individual o en su conjunto, excedan de \$1'000,000.00... La obligación de información a que se refiere este párrafo es aplicable incluso cuando las personas físicas no se encuentren obligadas a prestar declaración en los términos de otros artículos de esta Ley”. (LISR 2002, Art.108).

El $1^{\circ}$. De enero de 2003 se reformó la fracción III del artículo 107 de la Ley, sólo para sustituir el Capítulo VIII por el IX.

Igualmente, el $1^{\circ}$. De enero de 2003, el segundo párrafo del artículo 106 de la LISR se reformó sólo para suprimir la parte final que decía que “... La obligación de información a que se refiere este párrafo es aplicable incluso cuando las personas físicas no se encuentren obligadas a presentar declaración en los términos de otros artículos de esta Ley”. (LISR, 2003)

En 2004 se Reformó la Fracción I del Artículo 109 del Código Fiscal de la Federación.

El 6 de enero de 2004 se reformó la fracción I del artículo 109 de Código Fiscal de la Federación, sólo para referirse genéricamente a la Ley del Impuesto sobre la Renta, conforme al procedimiento establecido en ésta, para comprobar la discrepancia fiscal

Con la reforma a este artículo a partir del 1ero de enero del 2006 se prevé la posibilidad de iniciar el procedimiento de discrepancia fiscal en cualquier persona física, aún y cuando no esté inscrita en el RFC.

De acuerdo con Jiménez González resulta incuestionable que una política en materia de sanciones genera buenos resultados, sin embargo, en lo que respecta a su efectividad com- 
parte el quehacer con el órgano legislativo en virtud de que es éste el que tiene la atribución de definir los supuestos de las infracciones y delitos en materia fiscal, así como los mínimos y máximos de las sanciones y penas respectivas.15

La administración Pública está investida constitucionalmente de la Potestad Sancionadora la cual ejercen los tres poderes de la unión, así como los propios de las entidades federativas. Así, según Sánchez Narciso16el legislativo define y clasifica las faltas o infracciones, los delitos y las sanciones que han de aplicarse, la ejecución de las sanciones administrativas está a cargo del poder ejecutivo y al judicial le corresponde resolver las controversias entre los particulares y entre éstos y el Estado; por tanto el Estado dispone de la fuerza coactiva para hacer cumplir sus fallos. Los fundamentos constitucionales se expresan en los artículos 16, 22, 89 fracción I, y 73 fracción XXI de la Norma fundamental.

La Autoridad cuenta con una serie de herramientas par detectar cuando se incurre en discrepancia fiscal como son:

Declaraciones informativas de notarios, clientes y proveedores, pagos y retenciones a personas físicas, donativos efectuados, operaciones realizadas que causan IVA, operaciones en paraísos fiscales, pagos de dividendos, fideicomisos, pagos efectuados al extranjero, información de compañías de servicios (luz, teléfono, casa de bolsa, etc.) padrón de las AFORES, IMSS, INFONAVIT, Registro Público de la propiedad y comercio, adquisiciones de automóviles nuevos, intercambio de información con el INEGI, información del Sistema Bancario, cuentas bancarias, tarjetas de crédito, acuerdos internacionales de amplio intercambio de información tributaria.

Ya no es posible pasar inadvertido, la tecnología pone al descubierto al contribuyente, por lo que somos como libros abiertos ante la autoridad fiscal, quien descubrirá fácilmente a los que incurran en discrepancia fiscal.

Por ello es importante cuidar el comportamiento para no incurrir en tales ilícitos, si se quiere conservar el patrimonio y la libertad; pues tanto las personas no inscritas en el RFC, como las inscritas que manejen dinero o bienes, que no hayan declarado fiscalmente y por tanto no hayan pagado impuestos, corren peligro de enfrentar problemas penales de discrepancia fiscal y lavado de dinero, con la consecuente pérdida de su patrimonio y su libertad.

VIII. CONCLUSIONES

PRIMERA.- El 1º. De enero de 1980 se incluyó por primera vez la Discrepancia Fiscal en la Ley del Impuesto sobre la Renta. En 1980 la autoridad fiscal no contaba con controles y mecanismos para detectar en todos los casos la Discrepancia Fiscal, no obstante desde ese año se incluyó en nuestro sistema legal vigente, en espera de que en un futuro ya pudiera aplicarse plenamente.

La disposición que señalaba que "Las discrepancias que resulten de la aplicación de este precepto, no serán consideradas como constitutivas del delito de defraudación fiscal”, la cual se derogó a partir de 1983, no obstante lo cual, fue hasta 1992 cuando la Discrepancia Fiscal se tipificó como un delito equiparable a la defraudación fiscal.

\footnotetext{
${ }^{15}$ Jiménez, G. A. (2008) “Lecciones de Derecho Tributario", 9a. Edición, Thompson Editores,

${ }^{16}$ Sánchez N. (2003) “Derecho Fiscal Mexicano”, 3ª Edición, Editorial Porrúa, México, p.447)
} 
SEGUNDA.- A pesar que desde 1992 la Discrepancia Fiscal constituye un delito equiparable a la defraudación fiscal, y de que un gran número de contribuyentes incurría en ella, durante años enteros el texto legal que la tipifica como delito ha sido letra muerta por la falta de mecanismos y controles para que la autoridad fiscal pudiera detectar y demostrarla.

TERCERA.- Hoy en día, faltan todavía algunos controles y mecanismos para poder aplicar totalmente la Discrepancia Fiscal, los cuales se instrumentarán a la brevedad posible, por lo que prácticamente la autoridad fiscal ya está en condiciones de aplicarla plenamente, de donde queda clara la urgencia de que los contribuyentes corrijan su situación fiscal al respecto, de tal suerte que no pierdan su patrimonio ni su libertad.

CUARTA.- Con todo lo expuesto anteriormente se comprende fácilmente que estamos inmersos en una nueva realidad, que obliga a arribar a conclusiones novedosas y a formular recomendaciones inéditas, acordes con el actual entorno que nos envuelve.

QUINTA.- La autoridad fiscal, paulatina pero firmemente ha ido perfeccionando las leyes fiscales, introduciendo con visión de largo alcance cambios y adiciones que en su momento aún no eran aplicables por las condiciones existentes, pero que hoy en día ya pueden aplicarse en su totalidad, y con contundencia, gracias a los avances tecnológicos e informáticos alcanzados, sobre todo, por los controles y supervisión estricta que permite que las autoridades fiscales ejerzan sobre absolutamente todas las personas físicas, independientemente de que estén o no inscritas en el Registro Federal de Contribuyentes.

SEXTA.- Hoy los contribuyentes estamos permanentemente en la mira de las autoridades fiscales, quienes conocen todos nuestros movimientos, por lo que cualquier desviación o irregularidad en la que incurramos de inmediato será detectada, y con toda seguridad por las autoridades fiscales, antes de que extingan sus facultades legales de comprobación, y procederán en nuestra contra para exigir que respondamos legalmente por nuestro indebido proceder, por tanto, lo más conveniente es ajustar a derecho, en todo momento, nuestra actuación.

SÉPTIMA.- La evasión fiscal ya es prácticamente imposible, no se puede pasar inadvertido, pues la tecnología y la informática actuales ponen al descubierto estas anomalías, por lo que, sin excepción, estamos en la mira de la autoridad fiscal, quien fácilmente descubrirá a quienes indebidamente incurran en Discrepancia Fiscal o Lavado de dinero, por lo que es conveniente cuidar nuestro comportamiento para evitar el incurrir en tales ilícitos, si queremos conservar nuestro patrimonio, y nuestra libertad.

OCTAVA.- Sean particulares o servidores públicos, todas las personas físicas deben modificar radicalmente su conducta, de tal manera que en todas sus operaciones sólo manejen dinero que ya fue declarado para efectos fiscales, y por el cual ya se pagaron los impuestos respectivos.

NOVENA.- Las personas no inscritas en el Registro Federal de Contribuyentes que manejen dinero o bienes y las personas físicas inscritas en el Registro Federal de Contribuyentes que manejen dinero y bienes que no han sido declarados fiscalmente, y por tanto no se han 
pagado impuestos, corren verdadero peligro de enfrentar en el futuro problemas penales de Discrepancias Fiscales y Lavado de Dinero, con la consecuente pérdida de su patrimonio y su libertad, por lo que ambas anormalidades deben evitarse a toda costa.

IX. BIBLIOGRAFÍA

Domínguez, M. E. (2009) Código Fiscal de la Federación 16º Edición, Dofiscal Editores, México.

Garza de la, S. (2005) Derecho Financiero Mexicano, 17º. Edición, Editorial Porrúa, México.

Jiménez, G. A. (2008) Lecciones de Derecho Tributario, 9a. Edición, Thompson Editores, México.

Mabarak, D. (200o), Derecho Financiero Público, 2ª Edición, Editorial Mc GRAW-HILL, México.

Sánchez G. (1991), Derecho Fiscal mexicano, octava edición, Cárdenas editor y distribuidor, México|.

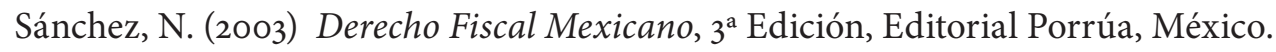

\section{FUENTES NORMATIVAS}

Ley del Impuesto Sobre la Renta 1979, Dofiscal Editores, México 1979.

Ley del Impuesto Sobre la Renta 1981, Dofiscal Editores, México 1981.

Ley del Impuesto Sobre la Renta 1983, Dofiscal Editores, México 1983.

Código Fiscal de la Federacion1992, Dofiscal Editores, México 1992.

Ley del Impuesto Sobre la Renta 1997, Dofiscal Editores, México 1997.

Ley del Impuesto Sobre la Renta 2001, Dofiscal Editores, México 2001.

Código Fiscal de la Federación 2004, Dofiscal Editores, México 2004.

Compilación Fiscal 2009, Dofiscal Editores, México 2009.

Compilación Fiscal 2012, Dofiscal Editores, México 2012 
